\title{
Focus
}

\section{De Geest van Christus en de Christus van de Geest}

H. van den Belt

Cornelis van der Kooi, This Incredibly Benevolent Force: The Holy Spirit in Reformed Theology and Spirituality (Grand Rapids: Eerdmans, 2018) 176 p., \$ 38.00 (ISBN 9780802876133) en Gijsbert van den Brink, Eveline van Staalduine-Sulman en Maarten Wisse (red.), The Spirit Is Moving: New Pathways in Pneumatology: Studies Presented to Professor Cornelis van der Kooi on the Occasion of His Retirement [Studies in Reformed Theology, 38] (Leiden: Brill, 2019) 410 p., € 143,00 (ISBN 9789004391734).

In het theologische oeuvre van Kees van der Kooi neemt het werk van de Heilige Geest een grote plaats in. Dit artikel schetst eerst in drie lijnen de contouren van zijn pneumatologie en biedt vervolgens een samenvatting van zijn Warfield Lectures (Princeton, 2014), gepubliceerd in This Incredibly Benevolent Force. Daarna komen enkele reacties op Van der Koois theologie in de afscheidsbundel aan de orde. De drie delen lopen steeds uit op een korte evaluatie.

\section{Openbaring}

Als gereformeerd predikant in Leimuiden promoveerde Van der Kooi cum laude op De denkweg van de jonge Karl Barth (1985). Kort daarna schreef hij in Trouw naar aanleiding van Barths $100^{\text {ste }}$ geboortedag over het wonder van de openbaring. 'God moet er zelf aan te pas komen om iets of iemand van Hem te laten spreken. Hij moet mensen zelf aanraken met zijn Geest, van buitenaf, zoals men een glas aan het klinken brengt.' Geïnspireerd door Barth is het thema van de openbaring hem altijd blijven intrigeren.

De pneumatologie helpt Van der Kooi om op zijn eigen neocalvinistische traditie en op Barth voort te borduren. Zo schetst hij in Wapenveld onder de titel 'Historiciteit als de achilleshiel van de gereformeerde spiritualiteit?' (2001) de ontwikkeling van de openbaringsleer in de Gereformeerde Kerken in Nederland. Bij Abraham Kuyper en Herman Bavinck is er op het punt van de historiciteit sprake van een zekere geslotenheid vanwege de kwetsbaarheid 
van de historische heilsfeiten; Gerrit Cornelis Berkouwer legt nadrukkelijker de verbinding van Gods openbaring met de menselijke ervaring. Terwijl Harry Kuitert de openbaring op laat gaan in de ervaring - alles is van beneden bouwt Van der Kooi constructief voort op de erfenis van Bavinck (correspondentie tussen object en subject) en Berkouwer (correlatie van openbaring en ervaring), door in lijn met Jan Veenhof de gereformeerde spiritualiteit te benadrukken. 'Geloofskennis of godskennis ontstaat en groeit in het veld van krachten waarin Woord (bijbel en verkondiging) en Geest (wat mij gewaar wordt en waar ik mij aan kan overgeven) beiden hun rol spelen' (14).

Die pneumatologische lijn in de openbaringsleer werkt hij ook uit in Als in een spiegel: God kennen volgens Calvijn en Barth (2002), in het Engels vertaald als As in a Mirror (2005), waarin de filosofie van Immanuel Kant fungeert als een scharnier van het tweeluik. Van der Kooi stelt in dit boek voor om het concept van Gods zelfopenbaring te verbreden. Het Woord blijft het criterium voor de ware kennis van God, maar die kennis is ook aanwezig in andere religies en in de filosofie en mag niet worden opgeofferd aan een identificatie van de Geest met het Woord. Vanuit de neocalvinistische traditie trekt hij bredere contouren voor de openbaring dan Barth.

In het licht van deze pneumatologische benadering van de openbaring is het niet verwonderlijk dat de door hem samen met Gijsbert van den Brink gepubliceerde Christelijke dogmatiek - geheel in lijn met de geloofsbelijdenis van Nicea en Constantinopel - de schriftleer plaatst in de context van de pneumatologie (hoofdstuk 12). Het hoofdstuk over de openbaring (hoofdstuk 5) staat echter meteen na de godsleer. Daarin krijgen de universele openbaring en de religies een belangrijke plaats. Voordat je over de Bijbel begint, moet je het eerst meer in het algemeen hebben over de wijze waarop God ons komt hinderen.

Daarin zit bij Van der Kooi ook een apologetisch motief. Hij is geen voorstander van de rationele apologetiek van het 'God bewijzen', maar ziet het onuitroeibare verlangen van de mens naar het oneindige en eeuwige wel als een vingerwijzing naar onze Schepper. Hij zoekt steeds naar een antwoord op de vraag hoe je de 'garstige breite Graben' van Gotthold Ephraim Lessing kunt overbruggen. Toen de universiteit van Groningen de vraag 'Bestaat God?' van de 7-jarige Anco aan een sterrenkundige voorlegde, reageerde die vrijzinnig: 'God bestaat in hoe jij en ik leven.' Van der Kooi schreef een alternatief antwoord in Trouw: 'Waar komen die sterren vandaan? Die zijn door God gemaakt. [...] Hij bestaat en ziet naar ons om.' Die grondtoon in zijn theologie werd tastbaar in de emotie waarmee Van der Kooi in zijn afscheidsrede vertelde hoe hij als jongen de donkere hemel inkeek. 'Spreekt God wel? Is Hij er wel?' 


\section{Charismatische vernieuwing}

Naast deze pneumatologische verbreding van de openbaringsleer, is Van der Kooi ook altijd zeer geïnteresseerd geweest in de charismatische vernieuwing en in de gaven van de Geest. Als geen ander heeft hij bijgedragen aan de wetenschappelijke doordenking van de betekenis van de charismatische beweging voor de kerk. Hij is sensitief voor de potentiële gevaren van die beweging, maar altijd vanuit een innerlijke betrokkenheid. Als bijzonder hoogleraar theologie van de charismatische vernieuwing heeft hij deze lijn uitgewerkt in het boek Tegenwoordigheid van Geest (2006), een bundeling van artikelen geschreven voor onder meer het Bulletin voor Charismatische Theologie. Daarin blijkt zijn openheid voor het doorgaande werk van de Geest, maar ook zijn kritische reflectie op geloofservaring als een pendant van de seculiere belevingscultuur en op het ongebroken optimisme van het overwinningsleven alsof de volmaaktheid van het koninkrijk al zou zijn aangebroken. Hij benadrukt de relatie tussen de Geest en de gemeente tegenover het individualistisch accent op de wedergeboorte of de charismata van de enkeling.

Zijn bijdrage aan de bezinning op de dienst der genezing is compact verwoord in de gezamenlijke verklaring van de Charismatische Werkgemeenschap Nederland en de Nederlandse Lucasorde, 'Gebed en genezing'. De pneumatologische lijnen die daarin getrokken worden verbinden de genezing als handelen van God aan de bredere werking en presentie van de Geest waardoor God mens en wereld vernieuwt. De dienst der genezing concurreert niet met de geneeskunde; beide zijn het werk van de helende en heilbrengende Geest, die ons ook leert zuchten onder de gebrokenheid en het lijden. Het was steeds zijn missie om in de gevestigde kerken het 'tegoed' van de charismatische beweging in te brengen, maar ook om de pinksterbeweging eraan te herinneren dat alles wat de Geest doet voorlopig is; we zijn pelgrims op weg naar het Godsrijk.

Het is heel mooi dat Van der Kooi als bruggenbouwer de gevestigde kerken herinnert aan het 'tegoed' van de charismatische beweging en tegelijk in charismatische kring aandacht vraagt voor de kritische functie voor het Woord, voor de kerk als eeuwen omspannende en wereldwijde gemeenschap van gelovigen, voor de gebrokenheid en voor het zuchten van de naar de voleinding verlangende Geest.

\section{Christologie}

Een derde lijn in Van der Koois werk is de verbinding van pneumatologie en christologie. Daar zit een ontwikkeling in die uitloopt op zijn pneumachristologie. In Hinkelen binnen de lijnen: Enkele krijtstrepen voor een christologie (1999) legt Van der Kooi de klassieke triniteitsleer en de twee naturen van 
Christus uit zonder daar kritische vragen bij te stellen. Weliswaar helt de vroege kerk in haar denken naar de kant van het God-zijn van Jezus Christus, maar 'het gewicht van de tweenaturenleer ligt bij de ene persoon van het eeuwige Woord, de Logos' (65). Er zijn sommigen die het over een andere boeg gooien om de menselijkheid van Jezus recht te doen. 'De belijdenis dat in Jezus God zelf tot de mens komt, wordt dan uitgedrukt in termen van Geest' (64). Van der Kooi staat daar niet onsympathiek tegenover, maar beschrijft het als een positie die hijzelf (nog) niet inneemt.

In een bijdrage aan Theologia Reformata, getiteld 'Die door de eeuwige Geest...' (2008), schrijft hij naar aanleiding van Hebreeën 9:11 dat de Geest de dragende grond is van wat Christus in zijn lijden doet; bijbels-theologisch gezien is de pneumatologie breder dan de christologie. Van der Kooi steekt nadrukkelijk in bij de concrete Jezus die gedragen en gedreven wordt door de Geest. De immanente triniteit is een hulpconstructie 'om dat wat we in de heilsgeschiedenis waarnemen te waarderen en in eerbied vast te houden' (210).

Zonder de Logoschristologie af te wijzen, ontwikkelt Van der Kooi vanuit een heilshistorische benadering een eigen Geestchristologie. Daarbij zoekt hij nadrukkelijk aansluiting bij de Reformatie. Johannes Calvijn wijst speculatie af en benadert de christologie vooral soteriologisch vanuit het besef dat wij Gods wezen en het mysterie van de incarnatie niet kunnen doorgronden (Van der Kooi in Calvijn: Handboek, 2008). Heiko Oberman ziet bij Calvijn een overgang van een tweenaturenchristologie naar een functionele christologie. 'Christus staat voor ons in zijn ambt, dat wil zeggen, in zijn functionaliteit voor mensen. Daartoe is Hij aangesteld en door de Geest gezalfd' (Van der Kooi in Handboek Heidelbergse Catechismus, 2013, 244).

In een aan Barend Kamphuis opgedragen bundel (2015) gaat hij nog een stap verder in de ontwikkeling van zijn pneumatheologie. Onder de titel 'De Geest als tegenwoordige en vernieuwende kracht' stelt hij dat de leer van de pneumatologie de mogelijkheid biedt om aan het onvruchtbare onderscheid tussen een hoge en een lage christologie voorbij te komen (60). De wijze waarop hij de geestchristologische benadering van Friedrich Schleiermacher samenvat, geeft ook zijn eigen positie goed weer: 'Doordat de Geest volledig bezit van hem heeft genomen is hij de Zoon' (62). Kennelijk is Van der Kooi in de ontwikkeling van zijn christologie op een essentieel punt geraakt door Schleiermacher, hoewel hij ook kritiek op hem heeft, met name op het feit dat het eigene van de Heilige Geest bij Schleiermacher gemakkelijk vervaagt en vervluchtigt. Van der Kooi zoekt nadrukkelijk naar een criterium om het werk van de Geest te onderscheiden van die van de geesten...

Samenvattend en evaluerend: Van der Kooi verbreedt de barthiaanse openbaringsleer vanuit het neocalvinistische accent op de universele openbaring, die 
hij enerzijds verbindt met het algemene werk van de Geest in de cultuur maar anderzijds ook met de zeer specifieke ervaring van de Geest in charismatische kring. Het is een spannende vraag wat de bredere benadering uiteindelijk doet met de christologie. Het accent verschuift van 'de Geest van Christus' naar 'de Christus van de Geest'.

\section{Warfieldlezingen}

Die accentverschuiving - méér is het ook niet omdat Van der Kooi steeds de nuance zoekt - blijkt ook uit zijn gepubliceerde Warfield-lezingen. This Incredibly Benevolent Force bestaat uit zes hoofdstukken. In het eerste komen vijf redenen voor de hernieuwde belangstelling voor de pneumatologie aan de orde: de aandacht voor religieuze ervaring, de trinitarische theologie, het recent bijbelonderzoek, de charismatische beweging en de oecumene.

Het tweede en derde hoofdstuk bieden onder de titels 'The Identity of Christ' en 'The Anointed Son' een samenvatting van Van der Koois christologie. Hij zet in bij Gods heilshandelen in de geschiedenis en pleit voor een integratie van de Geestchristologie in de Logoschristologie. Dat is beter dan de tweede door de eerste te vervangen, zoals Hendrikus Berkhof doet, of met Piet Schoonenberg beide naast elkaar te laten staan. Van der Kooi wil de Logoschristologie van de concilies aanvullen met pneumatologische elementen uit het bijbelse getuigenis (44). Protestanten moeten immers de traditie van de kerk kritisch tegen het licht van de Schriften houden.

Uitgangspunt voor het bepalen van de identiteit van Jezus is een heilshistorische benadering van het nieuwtestamentisch getuigenis: Jezus heeft zich geïdentificeerd met de God van Israël, de God van Israël heeft zich in de opstanding en verheerlijking geïdentificeerd met Jezus en Jezus is gezalfd met de Geest. De kernvraag luidt: 'Is de Logos God in eigen persoon die in onze wereld is gekomen en onze menselijke natuur heeft aangenomen?' (62). Vanuit het belijden van de vroege kerk zou je hier een volmondig ja verwachten, maar Van der Kooi houdt het spannend, door slechts op te merken dat het antwoord afhangt van de visie op de immanente triniteit. Hij combineert de lijnen van het 'opklimmende' model van de synoptische evangeliën met het 'neerdalende' model van Johannes en Paulus. Het eerste model benadrukt dat Jezus als jood leefde door de kracht van de Geest, het tweede verankert zijn zoonschap in God. 'We kunnen dus niet spreken van de Logos of de preexistentie los van het verhaal van Jezus Christus' (66).

Hoofdstuk 4, 'God's Spirit as transformative power', bespreekt drie stemmen uit de gereformeerde traditie: Johannes Calvijn, Friedrich Schleiermacher en Abraham Kuyper. Calvijns visie op Christus' hemelvaart is fundamenteel voor zijn theologie en spiritualiteit (75). Het extra-calvinisticum - het feit dat 
de godheid en de Geest van Christus ook buiten zijn menselijke natuur werkzaam zijn - opent perspectieven op de bredere werking van de Geest in de schepping en in de cultuur. Met dat laatste accent beweegt Van der Kooi zich geheel in lijn met de neocalvinistische Calvijnreceptie. Opmerkelijk is daarbij de verbinding van deze verbreding van het werk van de Geest aan Schleiermachers Gemeingeist. Het Koninkrijk van God begint voor Schleiermacher in de gelovige gemeenschap. Er loopt van Calvijn via Schleiermacher een lijn naar Kuyper voor wie de kerk als organisme een transformerende kracht in de wereld is.

De zalving van Christus met de Geest en het drievoudige ambt van de Christus en de christen vormen het thema van het volgende hoofdstuk. De dienst van de genezing is een voorbeeld van een vorm waarin de christen participeert in de zalving van Christus. Van der Kooi gebruikt hier het mooie beeld van elektrische leidingen met verborgen aansluitpunten. De gave van de profetie en het spreken in tongen verbindt hij creatief met zondag 12 van de catechismus. De Geest is een bruggenbouwer, de pontifex Maximus, die met Christus verbindt en zijn charismata uitdeelt (123).

Het slothoofdstuk is een pleidooi voor een derde weg van het kritisch onderscheiden van de geesten als alternatief voor de synthese van christendom en cultuur in de Middeleeuwen - maar ook bij Schleiermacher, Kuyper, Van Ruler en Berkhof - en de scheiding van christelijk geloof en cultuur bij Barth en Hauerwas. Overeenstemming met de apostolische geloofsbelijdenis, het feit dat de Geest naar Christus verwijst en herkenning in de gemeente van Christus zijn enkele van de criteria die Van der Kooi daarbij noemt voor het herkennen van Gods Geest in profetische bedieningen.

Samengevat: de openheid voor de algemene openbaring en voor het transformerende werk van de Geest blijkt uit te lopen op een nadrukkelijker accent op de heilshistorische economische triniteitsleer. De Geest die Jezus tot de Christus maakt krijgt de prioriteit boven een immanente triniteitsleer waarbij de eeuwige Zoon als de Logos in de volheid van de tijd de menselijke natuur aanneemt. Van der Kooi wil beide lijnen - de opklimmende en neerdalende - wel vasthouden, maar spreekt toch ook van een drastische herrinterpretatie en correctie van de klassieke Logoschristologie (65). Dat roept de vraag op of hij hierbij niet iets wezenlijks kwijtraakt, met name als het gaat om het belijdend spreken over de pre-existentie van Christus en over de immanente triniteit. Zijn zorg is dat een te ontologich spreken hierover de opklimmende lijn relativeert, maar als er over de pre-existentie niet meer gezegd kan worden dan dat Jezus staat voor wie God eigenlijk is (68) dan komt de neerdalende lijn wel erg onder druk te staan. 


\section{Bundel}

De mooie bundel met artikelen over de pneumatologie, aan Van der Kooi aangeboden ter gelegenheid van zijn emeritering, kent een thematische opzet langs de lijnen van Nicea-Constantinopel waar de Geest wordt beleden als Heer van de wereld, als degene die levend maakt, als degene die door de profeten heeft gesproken, als degene die ook uitgaat van de Zoon en als degene die de christelijke gemeenschap vormt. Achtereenvolgens komen de relaties tussen de Geest en de Bijbel, Christus, de wereld, de mens en de christelijke gemeenschap aan de orde. En passant geeft Gijsbert van den Brink in een voetnoot prijs dat het hoofdstuk over de Heilige Geest in de Christelijke dogmatiek van de hand van zijn collega komt.

Verschillende bijdragen werpen licht op Van der Koois pneumatologie. Eep Talstra leest het Oude Testament als een biografie van God en verbindt dat aan Van der Koois artikel in zijn eigen afscheidsbundel waar hij het extracalvinisticum relateert aan de incarnatie als de nieuwe manier waarin God bevestigt dat Hij God is (Van der Kooi, 'The Identity of Israël's God', 220). Talstra gaat verder dan Van der Kooi met zijn biografische benadering van Israëls God, maar zijn bijdrage doet wel vermoeden dat een van de bronnen van diens heilshistorische pneumachristologie gelegen is in de verbinding die hij als systematisch theoloog zocht met collega's uit de bijbelwetenschappen.

In zijn exegetische bijdrage behandelt Bert Jan Lietaert Peerbolte Romeinen 1:4 waar Paulus schrijft dat Jezus bij zijn opstanding als Zoon van God wordt aangesteld (appointed) door de Geest van de heiligheid. Hij vindt dat deze tekst in de Christelijke dogmatiek zorgvuldig gebruikt wordt, al roept de passage de vraag op wanneer Jezus dan volgens Paulus de Zoon van God geworden is. Hij signaleert bij Van der Kooi een openheid om de exegese daadwerkelijk in de systematische theologie te verwerken, ook als het gaat om zijn meest recente - en nog niet gepubliceerde - ideeën over 'novelty in God'.

De bijdrage van Arnold Huijgen gaat in op het extra-calvinisticum dat Van der Kooi de mogelijkheid biedt om het echt historische in de godsleer te verdisconteren en aan determinisme te ontkomen zonder in een vorm van open theïsme te vervallen. Geïnspireerd door Oepke Noordmans bij wie hij parallellen ziet met Van der Koois benadering van het extra-calvinisticum pleit hij voor een allegorische - maar wel aan de Schrift gebonden - lezing van het Oude Testament die kan bevrijden van de metafysische benadering van de patres. Het artikel doet niet alleen sterk denken aan Huijgens Lezen en laten lezen (2019) maar roept ook de opmerking in Van der Koois recensie van dat boek in herinnering: "De zuurdesem van de onbewogenheidstraditie moet uitgezuiverd worden uit het Godsbegrip en dus ook uit het bijbellezen", schrijft Huijgen (152). Dat is niets minder dan een programma.' 
Het tweede deel van de bundel over de christologie opent met een artikel van Henk Bakker over de pneumachristologie in de Syrische Oden van Salomo, een verzameling christelijke liederen en gebeden uit de vroege kerk. Hij merkt op dat de pneumachristologie dynamischer is dan de tweenaturenleer. In Bakkers boek Jezus (2020) is ook de invloed van het voortgaande gesprek met Van der Kooi te merken.

Abraham van de Beek legt in zijn bijdrage uit hoe het barthiaanse en het charismatische bij Van der Kooi samen kunnen gaan. Barth - God boven ons - en de pinksterchristenen - God in ons - lijken twee verschillende werelden, maar ze hebben ook gemeenschappelijke kenmerken, zoals het onhistorische denken. Daartegenover zijn Van der Koois pneumatologie en christologie juist voluit historisch. Van de Beek vindt het eigenlijk niet historisch genoeg vanwege de beperkte aandacht voor de historische kruisiging en de volle nadruk op de eschatologische opstanding van Christus. Hij waardeert in Van der Kooi de creatieve verbinding van Calvijns spreken over de sacramentele aanwezigheid van Christus en de charismatische concreetheid van de dienst der genezing.

In Jan Veenhofs hoofdstuk, waarin de grote congenialiteit met zijn leerling blijkt, staat de verbinding tussen Wijsheid en de Geest centraal. Wijsheid is meer dan intelligentie. De personificatie van de Wijsheid in Spreuken 8 brengt het begrip dicht bij de Logos. Veenhof trekt de lijn niet door naar de verhouding tussen Logos en Pneuma in de christologie, maar een nadere doordenking daarvan zou zeker de moeite waard zijn.

Gerard den Hertogs boeiende analyse van Van der Koois pneumatologie begint met kritiek op Barths sterke concentratie van de openbaring in Christus die zich ontwikkelt in het traceren van sporen van Gods presentie in het heden en in de ervaringen van het alledaagse leven en in de kritiek op het dualisme in de gereformeerde traditie die het universele en het zaligmakende werk van Christus en de Geest van elkaar scheidt.

Ten slotte werpt de bijdrage van Cory Willson, missioloog aan Calvin Theological Seminary en een van de promovendi van Van der Kooi, licht op de relevantie van diens pneumatologie voor de wereldwijde kerk en dan met name van het accent op discernment - het onderscheiden van het werk van de Geest, die altijd begint met een sterk bewustzijn van de eigen culturele context.

Helaas ontbreekt de ruimte om de artikelen te bespreken van Erik A. de Boer, Carl J. Bosma, Gijsbert van den Brink, Martien E. Brinkman, Gerrit C. van de Kamp, Miranda Klaver, Akke van der Kooi, Bruce L. McCormack, Richard J. Mouw, Eveline van Staalduine-Sulman, Benno van den Toren, Willem van Vlastuin, Pieter Vos, Michael Welker en Maarten Wisse. 


\section{Vragen}

Wellicht is het goed om enkele vragen te formuleren naar aanleiding van Van der Koois ontwikkeling die vooral een accentverschuiving is. In de eerste plaats benadrukt hij het belang van de onderscheiding tussen de Geest en de geesten en noemt hij het Woord als criterium. Onder de accentverschuiving van de klassieke Logoschristologie naar de Geestchristologie ligt echter ook een beweging van een visie op de Schrift als - min of meer tijdloos - getuigenis van wie God is naar een visie op de bijbelse geschriften als een narratief van de dramatische relatie tussen God en Israel. Van der Kooi gaat daarin een heel eind met Talstra mee. Het intrigeert en prikkelt, maar roept ook fundamentele vragen op naar de relatie tussen exegese en dogmatiek. Inderdaad, al is de canon afgesloten, het verstaan van het bijbelse getuigenis gaat door... Ook dat is het werk van de Geest, maar als de schriftleer vanuit de pneumatologie al te dynamisch wordt, hoe kan dan het Woord nog als criterium fungeren voor de herkenning van de Geest? Een dynamische Schrift leidt tot een dynamische God. Zou een beetje meer aseitas hier toch niet vruchtbaar kunnen zijn?

Daarnaast houdt Van der Koois accentverschuiving van de Logos- naar de Geestchristologie verband met zijn kritiek op de metafysische en filosofische vooronderstellingen waarmee de vroege kerk de klassieke triniteitsleer en christologie ontwikkelde. Hij verzet zich tegen een perfect-being theology en stelt dat in de klassieke theologie God gedetermineerd wordt door zijn simplicitas en daardoor onveranderlijk wordt. Nog afgezien van het feit dat de klassieke notie juist wil ontkennen dat God door iets gedetermineerd wordt, heeft de gedachte van Gods volmaaktheid ook bijbelse papieren. Recent nieuwtestamentisch onderzoek benadrukt de verwevenheid van Paulus' theologie met de contemporaine filosofie. Kan het klassieke denken over Gods volkomenheden niet ook welwillender geïnterpreteerd worden als een poging om met gebruikmaking van het antieke filosofische begrippenmateriaal recht te doen aan het bijbelse spreken over de eeuwige, alomtegenwoordige en alwetende God?

Van der Koois verschuiving van de Geest van Christus naar de Christus van de Geest houdt verband met zijn brede opvatting van het extra-calvinisticum. Hij verbreedt de gedachte van de alomtegenwoordigheid van de godheid en de Geest van de verhoogde Christus naar de Geest als zodanig. Maar kan het extra-calvinisticum van de verhoogde Christus al toegepast worden op de incarnatie? Van der Kooi wil niet dat de Geest à la Schleiermacher een algemeen principe wordt waarvan Christus een verbijzondering is, maar welke zekering zit er in zijn pneumatologie om dat te voorkomen? Waaiert het werk van de Geest niet toch te veel uit? Anderzijds is zijn voortdurend speu- 
ren naar sporen van de Geest van de Vader en de Zoon ook een poging om de afgrijselijke kloof tussen de wereld en God te overbruggen. Of liever een belijdenis van het geloof dat God die kloof steeds opnieuw verrassend en genadig overbrugt en het glas tot klinken brengt.

\section{Levensgezellen}

Het laatste woord is aan Margriet van der Kooi-Dijkstra, de meest beminde levensgezellin (amatissimae sociae vitae) aan wie This Incredibly Benevolent Force is opgedragen. Zij bespreekt in haar bijdrage aan de bundel de relevantie van de pneumatologie voor haar werk als ziekenhuispastor, waarvoor het impliciete theologische referentiekader bepalend is. De casus die zij daarbij inbrengt gaat over Elsbeth, een ongeneeslijk zieke vrouw van in de vijftig. Zij vraagt haar of zij weleens iets van God heeft ervaren. Eerst ontkent zij dat, maar bij doorvragen vertelt zij een verhaal van toen zij tien jaar oud was. Haar broertje van zeven is aangereden door een vrachtwagen en overleden. $\mathrm{Zij}$ voelt zich schuldig omdat zij hem niet kon redden en krijgt daarnaast verwijten van haar vader. Ongeveer een halfjaar later wordt ze 's nachts wakker en ze vertelt: 'Op een vreemde manier werd ik naar het raam getrokken; ik moest er naar toe. Daar, in de tuin, in de duisternis stond Jezus, in een helder licht, in witte kleding. Hij keek naar mij en ik keek naar Hem' (383). De ziekenhuispastor duidt haar verhaal: Jezus kwam om te zeggen dat het niet haar schuld was. Een pastor moet theologische vragen stellen en het leven van mensen durven duiden in de vaste overtuiging dat de Geest van God overal aanwezig en werkzaam is. Trefzekerder kan de pneumatologie van haar beminde levensgezel niet verwoord worden. 